\title{
The Tissue-Selective Estrogen Complex (Bazedoxifene/Conjugated Estrogens) for the Treatment of Menopause
}

\author{
Stefano Lello, Anna Capozzi, and Giovanni Scambia \\ Department of Woman and Child Health, Policlinico Gemelli Foundation, Largo Agostino Gemelli, Roma, Italy \\ Correspondence should be addressed to Stefano Lello; lello.stefano@gmail.com
}

Received 28 July 2017; Revised 23 October 2017; Accepted 30 October 2017; Published 5 December 2017

Academic Editor: Małgorzata Kotula-Balak

Copyright (C) 2017 Stefano Lello et al. This is an open access article distributed under the Creative Commons Attribution License, which permits unrestricted use, distribution, and reproduction in any medium, provided the original work is properly cited.

\begin{abstract}
The tissue-selective estrogen complex (TSEC) pairs conjugated estrogens (CE) with a selective estrogen receptor modulator (SERM), bazedoxifene acetate (BZA). A 2-year treatment with the TSEC improved vasomotor symptoms, quality of life, and vaginal atrophy in healthy postmenopausal women. In addition, the TSEC prevented vertebral and hip bone loss without increasing mammographic density, breast tenderness, the risk of myocardial infarction, stroke, or venous thromboembolism. Finally, the BZA $20 \mathrm{mg} / \mathrm{CE} 0.45 \mathrm{mg}$ dose did not increase the risk of endometrial hyperplasia. Based on these findings, the TSEC can be considered as a first-line treatment for symptomatic postmenopausal women.
\end{abstract}

\section{Introduction}

Traditional treatments for the management of menopause and postmenopause include hormone replacement therapy with estrogen and progestin (HT) or, for hysterectomized women, estrogen therapy (ET, with estrogen only). Other options are selective estrogen receptor modulators (SERMs) or condition-specific treatments, such as bisphosphonates, denosumab, or teriparatide for osteoporosis. It is widely accepted, as shown by the Women's Health Initiative (WHI), that using conjugated estrogens together with progestin (medroxyprogesterone acetate) in women with no prior hysterectomy to protect them from endometrial hyperplasia [1] is associated with an increased-although moderate (classified as "rare" $<1 / 1000$ per year) —risk of developing breast cancer [2]. However, treatment with conjugated estrogens reduces the breast cancer risk in women with prior hysterectomy (7 fewer cases in 100,000 per year) [3].

All the above-mentioned therapies can act as agonists or antagonists of estrogen receptors based on their chemical composition. From a clinical point of view, this translates in tissue-specific responses. For example, SERMs have estrogen agonist effects on bone tissue and antiestrogen effects on the breast and endometrium [4]. In particular, the only SERM indicated for vulvar-vaginal atrophy (VVA) is ospemifene [5].

Hence, based on the class of the molecule under study, the effects exerted on target tissues can be different, depending on the pharmacological action of single molecules or combination therapies (Table 1). The tissue-selective estrogen complex (TSEC) conjugates a SERM (20 mg bazedoxifene, BZA) with an estrogen compound (conjugated estrogens (CE), $0.45 \mathrm{mg}$ / day). The TSEC has been shown to have positive effects on hot flushes (and, in general, on menopausal symptoms), vagina, bone tissue, libido, and energy levels and neutral effects on the breast and uterus [10,11].

An ideal TSEC should, in fact, display the positive effects demonstrated by single compounds without having, or at least, minimizing any possible undesirable side effects [12].

Estrogens act on many tissues since both forms of estrogen receptors (ER- $\alpha$ and ER- $\beta$ ) are differently expressed throughout the body.

Indeed, classical target tissues for estrogen action include the brain (in which ER- $\alpha$ and ER- $\beta$ are expressed), [13, 14], uterus (mainly ER- $\alpha$ expression) [15], bone (ER- $\alpha$ and ER$\beta$ expression) $[16,17]$, breast (ER- $\alpha$ and ER- $\beta$ expression) [18], ovaries (ER- $\alpha$ and ER- $\beta$ expression) [14], and liver (ER- $\alpha$ expression) [19]. The chemical structure of CE, the 
TABLE 1: Targeted responses to systemic menopause treatments [6-11].

\begin{tabular}{lcccc}
\hline Target & $\begin{array}{c}\text { SERMs } \\
\text { Ral, BZA }\end{array}$ & Estrogen & $\begin{array}{c}\text { STEAR } \\
\text { (tibolone) }\end{array}$ & $\begin{array}{c}\text { TSEC } \\
(\mathrm{BZA} / \mathrm{CE})\end{array}$ \\
\hline Uterus & 0 & - & $=$ & 0 \\
Hot flushes & - & + & + & + \\
Vagina & - & + & + & + \\
Bone & + & + & + & + \\
Breast & + & 0 & $=$ & 0 \\
Sexual function & $=$ & + & ++ & + \\
Energy levels & $=$ & + & ++ & + \\
\hline
\end{tabular}

STERM: selective estrogen receptor modulator; Ral: raloxifene; BZA: bazedoxifene; STEAR: selective tissue estrogenic activity regulator (tibolone); TSEC: tissue selective estrogen complex $=\mathrm{BZA}+\mathrm{CE} ;+$ : positive effect; ++: very positive effect; -: negative effect; =: neutral effect.

estrogen component of the TSEC, is characterized by Bring-saturated molecules (classical estrogens) that act predominantly on ER- $\alpha$ and B-ring-unsaturated molecules (delta7-estrogen, delta6-8-estrogen, and delta8-estrogen) that act mainly on ER- $\beta$, originating an intrinsically balanced receptor modulation; of note, all CE are antioxidants [20].

As stated above, SERMs can bind to estrogen receptors $[8,21]$, with mixed agonist/antagonist activity depending on the genes and tissues being targeted. SERMs can mimic estrogen activity in some cases (agonist effect) and can inhibit estrogen action in other (antagonist effect) [22]. For this reason, SERMs have tissue-specific activity and can be ranked on an agonist/antagonist activity continuum [11].

The aim of this review was to summarize recent preclinical and clinical data on the action of the TSEC. We performed literature searches with PubMed for articles published in English after 2002 using the following keywords: TSEC, bazedoxifene, conjugated estrogens, HT, menopausal symptoms, quality of life, sexuality, bone, cardiovascular system, and oncologic risk.

\section{TSEC: Preclinical Data on Compounds Used Alone or in Association (Tables 2 and 3)}

2.1. Continuum of Antagonist/Agonist Activity: Selective Modulation of the Proliferation of Breast Cells (Cancer and Normal) in In Vitro Studies Using Animal Models (Table 2). BZA shows the best antagonist activity on the proliferation of breast cancer cells (MCF-7) according to the activity ranking of SERMs [23-25, 31].

As monotherapy, SERMs alone (either BZA, raloxifene, or tamoxifen) do not induce an antagonist or agonist effect on the proliferation of MCF-7 cells [25, 31]. However, in a study with MCF-7 cancer cells treated with CE in addition to single SERMs, all the molecules tested (BZA, raloxifene, and lasofoxifene) exerted an antagonist effect on the estrogen-induced MCF-7 cell proliferation. The activity ranking established for SERMs in MCF-7 cells was $\mathrm{BZA}>$ raloxifene $>$ lasofoxifene [25].
In addition, BZA was more effective than RLX and LAS in reducing ductal growth following estrogen stimulation in ovariectomized mice [26].

2.2. Selectivity and Endometrial Effects of SERMs: In Vivo Studies Using Animal Models. The action of different SERMs on the endometrial tissue can be assessed by their ability to increase uterine wet weight in various animal models. These data can be used to establish an agonist/antagonist activity ranking of SERMs in the endometrium.

BZA, either as monotherapy or in association with estrogens, induces the smallest effect on uterine wet weight in immature rats and ovariectomized mice or rats in comparison with controls treated with vehicle or with raloxifene and lasofoxifene $[8,22,32]$.

Raloxifene is a more potent antagonist than lasofoxifene $[8,26,32]$. Tamoxifen was shown to significantly increase uterine wet weight in ovariectomized rats, in comparison to control, to a relatively greater extent than raloxifene but not as much as $17 \beta$-estradiol. Furthermore, the uterine wet weight of ovariectomized immature mice was measured six hours after treatment with estrogens or SERM. In this study, BZA acted as an antagonist on the uterus since it did not increase uterine wet weight in comparison with control (vehicle). On the contrary, both raloxifene and lasofoxifene induced an increase in uterine wet weight compared to control. The antagonist effect on the uterus was higher with BZA, lower with raloxifene, and even lower with lasofoxifene [26].

BZA facilitates the degradation of ER- $\alpha$ on the uterus and breast [24, 30], exerting an antiestrogenic effect through the negative modulation of the receptor $\alpha$.

Overall, preclinical data show how the TSEC compounds bind to ER and how different SERMs have different effects on target tissues. The TSEC (BZA/CE) does not stimulate the endometrium (contrary to what happens with estrogens used alone or in association with some SERMs) nor the breast (as reported with estrogen and progestin therapy) $[24,26-28,30]$.

2.3. Bone Tissue Selectivity of SERMs: In Vivo Studies Using Animal Models. According to the activity ranking of SERMs in bone tissue, BZA, raloxifene, lasofoxifene, and tamoxifen all act as agonists, at different doses, and preserve bone mineral density (BMD) $[8,22,29,33,34]$.

BZA preserves bone mass in an osteopenic rat model after six weeks of treatment with $0.3 \mathrm{mg} / \mathrm{kg}$, a dose ten times inferior to the effective dose of raloxifene $(3 \mathrm{mg} / \mathrm{kg} / \mathrm{day})$, but higher than the necessary dose of estradiol $(2 \mu \mathrm{g})$ [8]. Kharode et al. showed that BZA ( $3.0 \mathrm{mg} / \mathrm{kg} /$ day $)$ significantly increases bone mass in ovariectomized rats in comparison with vehicle control and that the skeletal response is analogous to that obtained with CE (2.5 mg/kg/day) [29]. Lasofoxifene and raloxifene showed agonist activity in bone tissue similar to that seen with tamoxifen [33].

\section{TSEC: Clinical Trials}

Clinical trials designed to assess the activity of the TSEC have been performed on more than 7500 women around the world 
TABle 2: Preclinical studies on breast tissue.

\begin{tabular}{|c|c|c|}
\hline & Model & Results \\
\hline Song et al. [23] & MCF-7 breast cancer cells & $\begin{array}{l}\text { (i) BZA blocked CE-induced stimulation, including DNA synthesis, reduction of } \\
\text { apoptosis, expression of cMyc, pS2, and WNT1-inducible signaling pathway protein } 2\end{array}$ \\
\hline Wardell et al. [24] & MCF-7 breast cancer cells & (i) BZA showed inverse agonist activity on many genes regulated by estradiol \\
\hline Chang et al. [25] & $\begin{array}{l}\text { MCF-7 breast cancer cells } \\
\text { and microarrays }\end{array}$ & $\begin{array}{l}\text { (i) BZA, RLZ, and LAS inhibited the proliferation of breast cancer cells induced by CE, } \\
\text { with the following antagonist power: BZA > RLX > LAS } \\
\text { (ii) BZA inhibited a group of genes regulated by CE; this profile is different from those of } \\
\text { RLX and LAS }\end{array}$ \\
\hline Peano et al. [26] & Ovariectomized mice & $\begin{array}{l}\text { (i) The stimulating effects of CE on the expression of amphiregulin (a marker of ductal } \\
\text { proliferation) were antagonized by BZA }>\text { RLX }>\text { LAS } \\
\text { (ii) BZA was more effective than RLX and LAS in reducing ductal growth }\end{array}$ \\
\hline Song et al. [23] & Ovariectomized mice & $\begin{array}{l}\text { (i) BZA blocked gene expression induced by CE and the growth of mammary terminal } \\
\text { ducts and acini } \\
\text { (ii) BZA blocked tumor growth and gene expression in mice with MCF-7 xenografts }\end{array}$ \\
\hline Ethun et al. [27] & $\begin{array}{l}\text { Ovariectomized } \\
\text { cynomolgus macaques }\end{array}$ & $\begin{array}{l}\text { (i) 6-month treatment with BZA/CE significantly reduced the increase in epithelial } \\
\text { density, the growth, and the ductal proliferation induced by } \mathrm{CE} \text { (all } p<0.05 \text { ) } \\
\text { (ii) } \mathrm{BZA} / \mathrm{CE} \text { treatment reduced ER protein expression and activity markers }\end{array}$ \\
\hline
\end{tabular}

Table 3: Preclinical studies on endometrial tissue.

\begin{tabular}{|c|c|c|}
\hline & Model & Results \\
\hline Peano et al. [26] & Ovariectomized mice & $\begin{array}{l}\text { (i) BZA, in contrast to RLX or LAS, antagonized the increase in uterine wet weight to } \\
\text { levels similar to that induced by vehicle }\end{array}$ \\
\hline Oliva et al. [28] & $\begin{array}{l}\text { Ovariectomized } \\
\text { mitosis-luciferase mice }\end{array}$ & (i) BZA and CE completely inhibited the proliferative effects of CE in the uterus \\
\hline Kharode et al. [29] & Ovariectomized rats & (i) BZA/CE inhibited CE-induced uterine stimulation \\
\hline Komm and Lyttle [22] & Ovariectomized rats & $\begin{array}{l}\text { (i) } \mathrm{BZA} / \mathrm{CE} \text { reduced CE-induced uterine wet weight increase in a dose-dependent } \\
\text { manner }\end{array}$ \\
\hline Ethun et al. [30] & $\begin{array}{l}\text { Ovariectomized } \\
\text { cynomolgus macaques }\end{array}$ & $\begin{array}{l}\text { (i) Endometrial and epithelial proliferations were significantly reduced with } \mathrm{BZA} / \mathrm{CE} \\
\text { in comparison with } \mathrm{CE} \text { alone }(p<0.001) \\
\text { (ii) Endometrial hyperplasia rate following } \mathrm{BZA} / \mathrm{CE} \text { treatment was comparable to } \\
\text { controls }\end{array}$ \\
\hline
\end{tabular}

$[1-4,6]$, in a series of studies named SMART (Selective estrogens, Menopause, And Response to Therapy) [35-40].

3.1. Effects on Vasomotor Symptoms. The safety and efficacy of BZA $20 \mathrm{mg} / \mathrm{CE} 0.45 \mathrm{mg}$, the only authorized and clinically available dose in Italy, for the treatment of vasomotor symptoms in menopause were evaluated in the randomized, multicenter, double-blind, placebo-controlled SMART-1 clinical trial [35]. The SMART-1 enrolled 3397 healthy postmenopausal women, aged from 40 to 75 years, with an intact uterus. The results from SMART-1 show that both BZA $20 \mathrm{mg} / \mathrm{CE} 0.625$ and BZA $20 \mathrm{mg} / \mathrm{CE} 0.45 \mathrm{mg}$ significantly decrease the frequency and severity of hot flushes (HFs) in comparison with placebo. At week 12, the number of HFs was reduced by $51.7 \%$ to $85.7 \%$ with all doses and by $17.1 \%$ with placebo $(p<0.01)$. The effect on HFs was also observed during the randomized, double-blind, placebo-controlled SMART-2 trial [36] that lasted for 12 weeks. The SMART-2 trial was conducted in 318 healthy postmenopausal women with an intact uterus; 127 women were treated with BZA $20 \mathrm{mg} / \mathrm{CE} 0.45 \mathrm{mg}$ and 63 with placebo. Inclusion criteria defined menopause as at least 12 months of amenorrhea or
6 months of amenorrhea with levels of serum follicle stimulating hormone greater than $40 \mathrm{mIU} / \mathrm{mL}$. The mean age of the women enrolled in the study was 53 years (range: 42-64 years); mean years since menopause onset was 4.5 years; all women had natural menopause. Women had at least seven moderate or severe daily HFs or at least 50 weekly HFs at screening. Primary efficacy endpoints were changes from baseline of the mean number and score of daily HFs at weeks 4 and 12. Patients recorded HFs-related data on a daily diary card during screening and the entire period of the trial [37]. A statistically significant decrease in the frequency and severity of HFs was seen starting from week 4 in women treated with BZA $20 \mathrm{mg} / \mathrm{CE} 0.45 \mathrm{mg}$ compared to placebo $(p<0.001)$, which demonstrates the rapid action of TSEC.

3.2. Effects on Bone Tissue. The efficacy of the TSEC for the prevention of osteoporosis was assessed in two clinical trials (SMART-1 and SMART-5). The SMART-1 trial [41] enrolled 2315 healthy postmenopausal women (mean age: 56 years; range: $40-75$ years) assigned to two substudies. Substudy I $(n=1454)$ included women in menopause for more than five years who were osteopenic and had at least 
one additional osteoporosis risk factor. Substudy II $(n=861)$ enrolled women with less than five menopausal years with at least one additional osteoporosis risk factor. The endpoint was BMD changes as assessed by dual-energy X-ray absorptiometry (DXA) at the lumbar spine and total hip. A significant increase from baseline of mean BMD at the lumbar spine and hip was reported after 24 months of treatment with BZA $20 \mathrm{mg} / \mathrm{CE} 0.45 \mathrm{mg}$ (as well as with another dose investigated in the study: BZA $20 \mathrm{mg} / \mathrm{CE} 0.625 \mathrm{mg}$ ) in women in menopause for more than five years. Also, there was a statistically significant difference $(p<0.01)$ compared with placebo at each time point $(6,12$, and 24 months). A similar result was reported at the lumbar and total hip of women 1-5 years into postmenopause. In addition, there were differences in BMD between treatment groups (BZA $20 \mathrm{mg} / \mathrm{CE}$ $0.45 \mathrm{mg}$ or BZA $20 \mathrm{mg} / \mathrm{CE} 0.625 \mathrm{mg}$ ) and placebo at each time point ( $p<0.01$ at 6,12 , and 24 months). Changes in bone metabolism markers assessed in the SMART-1 trial (osteocalcin as bone formation marker and C-telopeptide as serum resorption marker) were significantly increased following treatment with all BZA/CE doses compared with placebo $(p<0.001)$. The study investigators concluded that $\mathrm{BZA} / \mathrm{CE}$ decreases bone turnover and bone loss in postmenopausal women with increased osteoporosis risk.

These data were confirmed by the one-year, doubleblind, randomized, placebo-controlled SMART-5 clinical trial [42], which enrolled 1886 women (mean age: 53 years; range: 40 to 60 years) postmenopausal for $1-5$ years and with at least one additional osteoporosis risk factor. Both BZA/CE doses induced better changes on the lumbar spine and total hip BMD than placebo after one year, with significant differences being observed at 6 and 12 months $(p<0.05)$. Also, BZA $20 \mathrm{mg} / \mathrm{CE} 0.45 \mathrm{mg}$ and BZA $20 \mathrm{mg} / \mathrm{CE} 0.625 \mathrm{mg}$ induced a more significant reduction from baseline of C-telopeptide and procollagen I N-terminal propeptide $(p<0.01)$. These data indicate a protective effect on bone metabolism as well as on BMD.

3.3. Effects on Sleep, Quality of Life, Sexual Function, and Treatment Satisfaction. The impact of the TSEC on sleep parameters, quality of life, and treatment satisfaction were assessed in two clinical trials [43, 44], using different tests, including the Medical Outcomes Study (MOS) Sleep Scale. The MOS Sleep Scale is composed of 12 items that assess sleep parameters with six subscales: sleep adequacy, sleep disturbance, sleep quantity, daytime somnolence, snoring, and waking with shortness of breath or a headache. The questionnaire also examines the average time taken to fall asleep (the score is calculated on a 6-point scale: $1=$ "all of the time" and $6=$ "none of the time"). The domains of the MOS Sleep Scale were examined by comparing treatment responders (subjects with at least 75\% improvement from baseline in the average number of moderate-to-severe daily HFs) and nonresponders. The impact on the quality of life (QoL) was assessed using the Menopause-Specific Quality of Life (MSQoL), a questionnaire comprising 29 items with four domains: vasomotor, psychosocial, physical, and sexual function. The MSQoL score is calculated as a mean of several items that range from 1 to 8 (where a maximum score corresponds to the most bothersome symptom). Treatment satisfaction was assessed with the Menopause Symptoms Treatment Satisfaction Questionnaire (MS-TSQ), comprising eight questions related to control of HFs during the day and control of HFs and sweats occurring during the night, sleep, mood, libido, ability to concentrate, medication tolerability, and overall satisfaction. Answers were scored from "extremely satisfied" to "extremely dissatisfied" on a 5-point scale.

Improvements were reported for the time to fall asleep, sleep disturbance, and adequacy for both doses (BZA $20 \mathrm{mg} / \mathrm{CE} 0.45 \mathrm{mg}$ and BZA $20 \mathrm{mg} / \mathrm{CE} 0.625 \mathrm{mg}$ ) at week 12 in comparison to placebo in the substudy SMART-5 $(p<0.05)$ [43]. In this study, both sleep and QoL were assessed. Also, significant improvements in sleep parameters were seen among responders treated with both doses of BZA/CE at week 12 in comparison with placebo in the trial SMART-2 $(p<0.05)$ [43].

Women being treated either with BZA $20 \mathrm{mg} / \mathrm{CE} 0.45 \mathrm{mg}$ or BZA 20/CE $0.625 \mathrm{mg}$ showed a significant improvement in QoL parameters at 1-year follow-up in the SMART-5 trial and 12 weeks in the SMART-2 $(p<0.001)$ and SMART-3 $(p>0.001)$ trials $[42,43]$. In the study SMART-3 [44], the effect of TSEC on QoL and sexual function was assessed. In this 12-week double-blind, placebo-controlled trial, conducted in 652 postmenopausal women with intact uterus and moderate-to-severe vulvar/vaginal atrophy, patients were randomized to treatment with daily BZA $20 \mathrm{mg} / \mathrm{CE}$ $0.45 \mathrm{mg}$, BZA $20 \mathrm{mg} / \mathrm{CE} 0.625 \mathrm{mg}$, BZA $20 \mathrm{mg}$, or placebo. At week 12, both BZA/CE doses induced a significant improvement in lubrification from baseline according to the Arizona Sexual Experiences (ASEX) Scale compared to placebo $(p<0.05)$. In addition, at 12 weeks, the MENQOL questionnaire showed significant improvements in vasomotor function, sexual function, and total score with BZA $20 \mathrm{mg} / \mathrm{CE} 0.45$ and BZA $20 \mathrm{mg} / \mathrm{CE} 0.625 \mathrm{mg}(p<0.001)$. MS-TSQ results showed that patients treated with $\mathrm{BZA} / \mathrm{CE}$ were overall more satisfied with treatment as well as with the day and night control of HFs, quality of sleep, mood, and emotions compared with patients treated with BZA $20 \mathrm{mg}$ or placebo ( $p<0.05$ for all comparisons).

3.4. Effects on Vaginal Tissue. Data from vaginal smears showed that the TSEC significantly increased the number of superficial and intermediate cells while decreasing the percentage of parabasal cells, which displays an estrogen-like action that can improve menopausal vaginal atrophy. In the SMART-1 trial [35], a randomized, multicenter, doubleblind, placebo-, and active-controlled trial, carried out in 3397 menopausal women with an intact uterus (mean age: 56 years; range: $40-75$ years) for 2 years, the groups treated with BZA $20 \mathrm{mg} / \mathrm{CE} 0.45$ and BZA $20 \mathrm{mg} / \mathrm{CE} 0.625 \mathrm{mg}$ showed a significant increase in the number of superficial and intermediate cells and a reduction in the number of parabasal cells $(p<0.001$ versus placebo).

The action of the TSEC on vaginal tissue was also studied in the multicenter, double-blind, randomized, placebo-, and active-controlled trial SMART-3 trial [36]. The objective of this study was to compare the efficacy and safety of two doses 
of $\mathrm{BZA} / \mathrm{CE}$ versus placebo for the treatment of moderatesevere menopause-associated VVA. The SMART-3 trial enrolled 664 healthy menopausal women (age range: 40-65 years) who were randomized to the following treatment groups: daily BZA $20 \mathrm{mg} / \mathrm{CE} 0.625 \mathrm{mg}, \mathrm{BZA} 20 \mathrm{mg} / \mathrm{CE}$ $0.45 \mathrm{mg}$, BZA $20 \mathrm{mg}$, or placebo during 12 weeks. VVArelated parameters were assessed at screening, week 4, and week 12. Adverse events were recorded during the entire period of study. Groups treated with BZA $20 \mathrm{mg} / \mathrm{CE}$ $0.625 \mathrm{mg}$ and BZA $20 \mathrm{mg} / \mathrm{CE} 0.45 \mathrm{mg}$ showed more superficial cells and fewer parabasal cells in comparison with placebo $(p<0.01)$. Also, significant improvement in vaginal dryness was observed for both groups treated with BZA/CE compared to placebo $(p<0.05)$. Adverse events were not different between groups. The authors concluded that BZA/ $\mathrm{CE}$ was efficient for the treatment of moderate/severe VVA in menopausal women.

3.5. Effects on Endometrial Tissue. The action of the TSEC on the endometrium was evaluated in the randomized, doubleblind, placebo-, and active-controlled (raloxifene $60 \mathrm{mg}$ ) SMART-1 trial [45]. The drugs investigated in SMART-1 were BZA $(10,20$, or $40 \mathrm{mg})$ in combination with CE $(0.625$ or $0.45 \mathrm{mg}$ ), daily raloxifene, or placebo for two years. The study population was composed of healthy postmenopausal women $(n=3397)$, aged from 40 to 75 years, with an intact uterus and a body mass index $\leq 32.2 \mathrm{~kg} / \mathrm{m}^{2}$. The primary endpoint was the incidence of endometrial hyperplasia at 12 months. Endometrial biopsies were performed at screening and months 6,12 , and 24; biopsies were evaluated by two pathologists blinded to treatment; transvaginal ultrasounds were carried out to assess endometrial thickness, ovarian volume, and the presence of ovarian cysts, at the screening and months 12 and 24. Treatment with BZA $20 \mathrm{mg} / \mathrm{CE} 0.625 \mathrm{mg}$ or BZA $20 \mathrm{mg} / \mathrm{CE} 0.45 \mathrm{mg}$ was associated with a low rate $(<1 \%)$ of endometrial hyperplasia that was not significantly different from that observed with placebo during the 24 months of the study. Also, the endometrial thickness in patients treated with BZA (20 or $40 \mathrm{mg}$ )/CE $(0.625$ or $0.45 \mathrm{mg})$ was not significantly different from patients treated with placebo. Groups treated with BZA $10 \mathrm{mg} / 0.625 \mathrm{mg}$ CE or BZA $10 \mathrm{mg} / \mathrm{CE} 0.45 \mathrm{mg}$ showed an increased number of hyperplasia cases. Thus, the lowest effective dose of BZA capable of significantly inhibit the endometrial-stimulating effect induced by $\mathrm{CE} 0.45 \mathrm{mg}$ and 0.625 was $20 \mathrm{mg} /$ day. This study showed that, while administering CE to patients, endometrial protection can be achieved through the modulation of ER by BZA. In the SMART- 5 trial [41], the endometrial effects of BZA/CE were also studied: hyperplasia rate was $<1 \%$ and no significant differences were observed in comparison with placebo after 12 months of BZA $20 \mathrm{mg} / \mathrm{CE} 0.45 \mathrm{mg}$ treatment.

3.6. Effects on Uterine Bleeding. The observed endometrial action of the TSEC indicates an optimal balance between its two components, BZA $20 \mathrm{mg} / \mathrm{CE} 0.45 \mathrm{mg}$ or BZA $20 \mathrm{mg} / \mathrm{CE}$ $0.625 \mathrm{mg}$. This balance is also displayed by the high percentage of amenorrhea observed in patients. Indeed, in the SMART-1 and SMART-5 trials $[42,46]$, the cumulative amenorrhea rate during the first year of treatment was $83 \%$ for patients treated with BZA $20 \mathrm{mg} / \mathrm{CE} 0.45 \mathrm{mg}$, a rate similar to that observed for placebo-treated patients (SMART-1). Furthermore, treatment with BZA $20 \mathrm{mg} / \mathrm{CE}$ $0.45 \mathrm{mg}$ induced a high percentage of amenorrhea that was different from that obtained with CE $0.45 \mathrm{mg} /$ medroxyprogesterone acetate $1.5 \mathrm{mg}(p<0.001)$ in 13 observation cycles [42]. Bleeding-related adverse events were significantly lower in BZA $20 \mathrm{mg} / \mathrm{CE} 0.45 \mathrm{mg}$ and BZA $20 \mathrm{mg} /$ CE $0.625 \mathrm{mg}$ groups (7\% and $5.7 \%$, resp.) compared to those reported for treatment with $\mathrm{CE} 0.45 \mathrm{mg} / \mathrm{MPA}$ $1.5 \mathrm{mg}(22.3 \%)$ (overall $p<0.001$ ) [42].

3.7. Effects on Breast Tissue. The action of the TSEC on breast tissue was evaluated in the randomized, double-blind, placebo-, and active-controlled (CE/MPA) SMART-5 trial [39]. The SMART-5 investigated the effect of BZA/CE on mammographic density and other breast parameters in a substudy that enrolled 940 women with technically acceptable digital mammograms at screening and 12 months. The treatments under study were BZA $20 \mathrm{mg}$ and CE 0.45 or $0.625 \mathrm{mg}$, placebo, BZA $20 \mathrm{mg}$, and $\mathrm{CE}(0.45 \mathrm{mg})+\mathrm{MPA}$ $(1.5 \mathrm{mg})$. Mammograms were read centrally by a single radiologist blinded to treatment and time sequence of exams; percent breast density was determined using a validated software. The noninferiority of treatments was based on a predefined margin of $1.5 \%$ for a comparison of adjusted breast density mean differences at 12 months. BZA $20 \mathrm{mg}$ and CE $0.45 \mathrm{mg}$ or $0.625 \mathrm{mg}$ demonstrated noninferiority compared to placebo in respect to breast density. Mammographic density decreased from baseline with BZA $20 \mathrm{mg} / \mathrm{CE} 0.45$ $(-0.38 \%)$, BZA $20 \mathrm{mg} / \mathrm{CE} 0.625 \mathrm{mg}(-0.44 \%)$, and placebo $(-0.32 \%)$ and significantly increased from baseline with CE $0.45 \mathrm{mg} / \mathrm{MPA} 1.5 \mathrm{mg}(+1.60 \%, p<0.001$ versus placebo). Both doses of BZA/CE showed breast tenderness rates (expressed as the percentage of women with breast tenderness for one or more days) similar to placebo and significantly lower than those induced by CE $0.45 \mathrm{mg} /$ MPA $(p<0.001)$. Furthermore, no differences in adverse events between groups were reported. Breast cancer rates were low and with no significant differences among groups: BZA $20 \mathrm{mg} / \mathrm{CE} 0.45 \mathrm{mg}, 0.4 \%$; BZA $20 / \mathrm{CE} 0.625$, $0 \%$; MPA $1.5 /$ CE $0.45,0.5 \%$; placebo, $0.2 \%$. In conclusion, in this study, BZA $20 \mathrm{mg}$ and CE $0.45 \mathrm{mg}$ or $0.625 \mathrm{mg}$ did not increase mammographic density nor breast tenderness during one year of follow-up and presented a favorable safety profile for breast tissue.

In another trial [47], a randomized, placebo-, and activecontrolled trial carried out on mammograms from 507 women (age range: 55.2-56.3 years) evaluated the effect of BZA $20 \mathrm{mg} / \mathrm{CE} 0.45 \mathrm{mg}$, BZA $20 \mathrm{mg} / \mathrm{CE} 0.625 \mathrm{mg}$, raloxifene $60 \mathrm{mg}$, and placebo on breast tissue for two years. Mammograms were also read by a radiologist blinded to treatment and to the date in which mammograms were performed; changes in breast density were also assessed with validated software. Mean mammographic density changes from baseline at 24 months were the following: BZA $20 \mathrm{mg} / \mathrm{CE}$ $0.45 \mathrm{mg},-0.39 \%$; BZA $20 \mathrm{mg} / \mathrm{CE} 0.625 \mathrm{mg},-0.05 \%$; raloxifene $60 \mathrm{mg},-0.23 \%$; placebo, $-0.42 \%$. Reductions in 
TABLE 4: Cardiovascular events (venous thromboembolism, stroke, and coronary artery disease) reported in SMART trials (data presented as incidence per 1000 women/year, CI 95\%) [53].

\begin{tabular}{lccr}
\hline Dose & Venous thromboembolism & Stroke & Coronary artery disease \\
\hline BZA $20 \mathrm{mg} /$ CE $0.45 \mathrm{mg}$ & $0.3(0.0-2.0)$ & $0.4(0.0-2.4)$ & $2.6(0.0-5.6)$ \\
BZA 20 mg/CE 0.625 mg & $0(0.0-1.5)$ & $0.2(0.0-1.9)$ & $1.4(0.0-3.9)$ \\
BZA/CE all doses & $0.7(0.0-1.5)$ & $0.44(0.0-1.1)$ & $2.4(1.0-3.7)$ \\
Placebo & $0.6(0.0-2.9)$ & $0.0(0.0-1.7)$ & $2.0(0.0-5.2)$ \\
\hline
\end{tabular}

mammographic density from baseline were statistically significant for BZA $20 \mathrm{mg}$ CE $0.45 \mathrm{mg}$ and placebo. Based on these data, treatment with BZA/CE up to 2 years did not increase mammographic density or breast tenderness, and there was no evidence of an increased breast cancer risk, which suggests that TSEC has a better breast-related safety profile than traditional hormone replacement therapies [48]. These outcomes may be related to the fact that TSEC is the first hormonal treatment for menopause without progestin. Neither conjugated estrogens alone (contrary to the formulation conjugated estrogens plus progestin) nor BZA alone demonstrated breast cancer increased risk in previous studies [49-51].

3.8. Effects on Lipid and Coagulation Parameters. In the SMART-1 trial [35], carried out in healthy postmenopausal women with an intact uterus $(n=3397$, aged from 40 to 75 years), LDL cholesterol levels decreased, and HDL cholesterol levels increased during two years of treatment with the TSEC. Overall, the impact on coagulation parameters (antithrombin III, protein C, protein S, fibrinogen, partial thromboplastin time, prothrombin time, and D-dimer) and lipid parameters did not show clinically significant changes. A pooled analysis of data from the SMART trials confirmed these results [48]. After analyzing data obtained with BZA $20 \mathrm{mg} / \mathrm{CE} 0.45 \mathrm{mg}$, BZA $20 \mathrm{mg} / \mathrm{CE} 0.625 \mathrm{mg}$, and placebo for 12 months, the authors observed that BZA $20 \mathrm{mg} / \mathrm{CE} 0.45 \mathrm{mg}$ and BZA $20 \mathrm{mg} / \mathrm{CE} 0.625$ induced significant improvements in total cholesterol $(-4.20$ and $-4.37 \%$ versus $-0.88 \%)$, LDL cholesterol ( -9.33 and $-10.78 \%$ versus $-1.08 \%)$, HDL cholesterol (4.59 and $6.21 \%$ versus $1.30 \%$ ), and LDL/HDL ratio LDL/ HDL ( -11.59 and $-14.00 \%$ versus $-0.84 \%)$ compared to placebo. On the other hand, triglycerides were increased from baseline with both doses $(p<0.001)$ in comparison with placebo $(15.13 \%$ and $15.74 \%$ versus $4.43 \%)$ as generally reported with the oral administration of estrogen, but this aspect is considered not clinically relevant. These trends were confirmed by the results obtained at 24 months. Thus, the TSEC is associated with predominantly favorable changes in lipid parameters for up to 2 years of treatment in postmenopausal women.

3.9. Cardiovascular Effects. Cardiovascular effects were assessed in the SMART-1 trial performed on healthy postmenopausal (for at least 1 year) women $(n=3397)$ age $40-$ 75 with an intact uterus (body mass index $\leq 32.2 \mathrm{~kg} / \mathrm{m}^{2}$ ) [35]. The incidence of cardiovascular adverse events was low $(<1 \%)$ across treatment groups and with no significant differences. BZA $20 \mathrm{mg} / \mathrm{CE} 0.45 \mathrm{mg}$ and BZA $20 \mathrm{mg} / \mathrm{CE}$ $0.625 \mathrm{mg}$ did not show differences in the incidence of myocardial infarction, coronary artery disease, coronary artery insufficiency, and venous thromboembolic events compared to placebo after a 2-year follow-up [35]. The incidence of these conditions after two years was as follows:

(i) Risk of acute myocardial infarction (AMI) with $\mathrm{BZA} / \mathrm{CE}$ versus $\mathrm{PBO}=0.48$ (CI 95\%: 0.05-4.66)

(ii) Risk of coronary artery disease (CAD)/coronary artery insufficiency with BZA/CE versus $\mathrm{PBO}=1.29$ (CI 95\%: 0.16-10.34)

(iii) Risk of venous thromboembolism (VTE) with BZA/ CE versus $\mathrm{PBO}(\mathrm{RR}=0.48$; $\mathrm{CI}$ 95\%: 0.05-4.66)

It is noteworthy that not only there is no increase in artery disease but also venous disease is not increased after two years of treatment with the TSEC. In addition, body weight increased by less than $0.9 \mathrm{~kg}$ and BMI by less than $0.4 \mathrm{~kg} / \mathrm{m} 2$ with BZA $20 \mathrm{mg} / \mathrm{CE} 0.45$, BZA $20 \mathrm{mg} / \mathrm{CE} 0.625$, and placebo at $3,6,12$, and 24 months of follow-up [52], which suggests a neutral metabolic impact.

A meta-analysis of all five SMART trials [53] evaluated cardiovascular safety data from healthy postmenopausal women that were given at least one dose of BZA $20 \mathrm{mg} / \mathrm{CE}$ $0.45 \mathrm{mg}(n=1585)$ and BZA $20 \mathrm{mg} / \mathrm{CE} 0.625 \mathrm{mg}(n=1583)$, any dose of BZA/CE $(n=4868)$ or placebo $(n=1241)$ for a follow-up period of up to 2 years. Events of venous thromboembolism (VTE), coronary artery disease (CHD), and cerebrovascular events (stroke) were assessed. Rates per 100 women/year are presented in Table 4.

For any dose of BZA/CE, the relative risk (CI 95\%) of VTE was $0.5(0.1-1.8)$, of stroke was $0.5(0.1-2.6)$, and of coronary disease was $0.63(0.23-1.74)$, with no significant differences with placebo. This meta-analysis indicates that for up to 2 years of treatment, BZA $20 \mathrm{mg} / \mathrm{CE} 0.45 \mathrm{mg}$ and BZA $20 \mathrm{mg} / \mathrm{CE} 0.625 \mathrm{mg}$ present an acceptable cardiovascular safety profile, with rates of stroke and coronary artery disease similar to placebo in healthy postmenopausal women. Also, the risk of VTE was low [53].

\section{Conclusion: Role of the TSEC in the Management of Menopausal Patients}

Overall, data from the literature demonstrates that the TSEC

(i) significantly reduces vasomotor symptoms and increases the quality of sleep (improving the quality of life),

(ii) protects bone tissue, 
(iii) improves vaginal atrophy,

(iv) does not stimulate breast tissue,

(v) does not stimulate endometrial tissue,

(vi) does not increase cardiovascular risk.

Considering the clinical pharmacology characteristics of a TSEC, this novel drug class, particularly the combination BZA $20 \mathrm{mg} / \mathrm{CE} 0.45 \mathrm{mg}$, may represent the first choice in the treatment of patients with severe symptoms during the early phases of menopause. This conclusion is also based on breast- and uterus-related safety data obtained so far and on the positive effects on vaginal atrophy and bone tissue that should be considered when providing menopausal women with a personalized therapy.

\section{Conflicts of Interest}

Stefano Lello, Anna Capozzi, and Giovanni Scambia declare that they have no conflicts of interest.

\section{References}

[1] J. D. Woodruff and J. H. Pickar, "Incidence of endometrial hyperplasia in postmenopausal women taking conjugated estrogens (Premarin) with medroxyprogesterone acetate or conjugated estrogens alone," American Journal of Obstetrics \& Gynecology, vol. 170, no. 5, pp. 1213-1223, 1994.

[2] R. T. Chlebowski, G. L. Anderson, M. Gass et al., "Estrogen plus progestin and breast cancer incidence and mortality in postmenopausal women," JAMA, vol. 304, no. 15, pp. 16841692, 2010.

[3] G. L. Anderson, R. T. Chlebowski, A. K. Aragaki et al., "Conjugated equine oestrogen and breast cancer incidence and mortality in postmenopausal women with hysterectomy: extended follow-up of the Women's Health Initiative randomised placebo-controlled trial," The Lancet Oncology, vol. 13, no. 5, pp. 476-486, 2012.

[4] J. H. Pickar, T. MacNeil, and K. Ohleth, "SERMs: progress and future perspectives," Maturitas, vol. 67, no. 2, pp. 129$138,2010$.

[5] N. Bruyniks, R. E. Nappi, C. Castelo-Branco, T. J. de Villiers, and J. Simon, "Effect of ospemifene on moderate or severe symptoms of vulvar and vaginal atrophy," Climacteric, vol. 19, no. 1, pp. 60-65, 2016.

[6] J. V. Pinkerton, D. F. Archer, W. H. Utian et al., "Bazedoxifene effects on the reproductive tract in postmenopausal women at risk for osteoporosis," Menopause, vol. 16, no. 6, pp. 1102-1108, 2009.

[7] S. Ronkin, R. Northington, E. Baracat et al., "Endometrial effects of bazedoxifene acetate, a novel selective estrogen receptor modulator, in postmenopausal women," Obstetrics \& Gynecology, vol. 105, no. 6, pp. 1397-1404, 2005.

[8] B. S. Komm, Y. P. Kharode, P. V. Bodine, H. A. Harris, C. P. Miller, and C. R. Lyttle, "Bazedoxifene acetate: a selective estrogen receptor modulator with improved selectivity," Endocrinology, vol. 146, no. 9, pp. 3999-4008, 2005.

[9] N. Biglia, S. Maffei, S. Lello, and R. E. Nappi, "Tibolone in postmenopausal women: a review based on recent randomised controlled clinical trials," Gynecological Endocrinology, vol. 26, no. 11, pp. 804-814, 2010.

[10] B. L. Riggs and L. C. Hartmann, "Selective estrogen-receptor modulators-mechanisms of action and application to clinical practice," The New England Journal of Medicine, vol. 348, no. 7, pp. 618-629, 2003.

[11] B. S. Komm, "Review article: a new approach to menopausal therapy: the tissue selective estrogen complex," Reproductive Sciences, vol. 15, no. 10, pp. 984-992, 2008.

[12] B. S. Komm, S. Mirkin, and S. N. Jenkins, "Development of conjugated estrogens/bazedoxifene, the first tissue selective estrogen complex (TSEC) for management of menopausal hot flashes and postmenopausal bone loss," Steroids, vol. 90, pp. 71-81, 2014.

[13] M. K. Osterlund, K. Grandien, E. Keller, and Y. L. Hurd, "The human brain has distinct regional expression patterns of estrogen receptor $\alpha$ mRNA isoforms derived from alternative promoters," Journal of Neurochemistry, vol. 75, no. 4, pp. 1390-1397, 2000.

[14] M. González, A. Cabrera-Socorro, C. G. Pérez-García et al., "Distribution patterns of estrogen receptor $\alpha$ and $\beta$ in the human cortex and hippocampus during development and adulthood," The Journal of Comparative Neurology, vol. 503, no. 6, pp. 790-802, 2007.

[15] G. Pelletier and M. El-Alfy, "Immunocytochemical localization of estrogen receptors $\alpha$ and $\beta$ in the human reproductive organs," The Journal of Clinical Endocrinology \& Metabolism, vol. 85, no. 12, pp. 4835-4840, 2000.

[16] V. Kusec, A. S. Virdi, R. Prince, and J. T. Triffitt, "Localization of estrogen receptor- $\alpha$ in human and rabbit skeletal tissues," The Journal of Clinical Endocrinology \& Metabolism, vol. 83, no. 7, pp. 2421-2428, 1998.

[17] O. Vidal, L. G. Kindblom, and C. Ohlsson, "Expression and localization of estrogen receptor- $\beta$ in murine and human bone," Journal of Bone and Mineral Research, vol. 14, no. 6, pp. 923-929, 1999.

[18] S. Li, B. Han, G. Liu et al., "Immunocytochemical localization of sex steroid hormone receptors in normal human mammary gland," The Journal of Histochemistry \& Cytochemistry, vol. 58, no. 6, pp. 509-515, 2010.

[19] G. G. J. M. Kuiper, B. Carlsson, K. Grandien et al., "Comparison of the ligand binding specificity and transcript tissue distribution of estrogen receptors $\alpha$ and $\beta$," Endocrinology, vol. 138, no. 3, pp. 863-870, 1997.

[20] B. R. Bhavnani and F. Z. Stanczyk, "Pharmacology of conjugated equine estrogens: efficacy, safety and mechanism of action," The Journal of Steroid Biochemistry and Molecular Biology, vol. 142, pp. 16-29, 2014.

[21] A. L. Wijayaratne, S. C. Nagel, L. A. Paige et al., "Comparative analyses of mechanistic differences among antiestrogens," Endocrinology, vol. 140, no. 12, pp. 5828-5840, 1999.

[22] B. S. Komm and C. R. Lyttle, "Developing a SERM: stringent preclinical selection criteria leading to an acceptable candidate (WAY-140424) for clinical evaluation," Annals of the New York Academy of Sciences, vol. 949, pp. 317326, 2001.

[23] Y. Song, R. J. Santen, J.-p. Wang, and W. Yue, "Effects of the conjugated equine estrogen/bazedoxifene tissue-selective estrogen complex (TSEC) on mammary gland and breast cancer in mice," Endocrinology, vol. 153, no. 12, pp. 57065715, 2012. 
[24] S. E. Wardell, E. R. Nelson, C. A. Chao, and D. P. McDonnell, "Bazedoxifene exhibits antiestrogenic activity in animal models of tamoxifen-resistant breast cancer: implications for treatment of advanced disease," Clinical Cancer Research, vol. 19, no. 9, pp. 2420-2431, 2013.

[25] K. C. N. Chang, Y. Wang, P. V. N. Bodine, S. Nagpal, and B. S. Komm, "Gene expression profiling studies of three SERMs and their conjugated estrogen combinations in human breast cancer cells: insights into the unique antagonistic effects of bazedoxifene on conjugated estrogens," The Journal of Steroid Biochemistry and Molecular Biology, vol. 118, no. 1-2, pp. 117-124, 2010.

[26] B. J. Peano, J. S. Crabtree, B. S. Komm, R. C. Winneker, and H. A. Harris, "Effects of various selective estrogen receptor modulators with or without conjugated estrogens on mouse mammary gland," Endocrinology, vol. 150, no. 4, pp. 18971903, 2009.

[27] K. F. Ethun, C. E. Wood, T. C. Register, J. M. Cline, S. E. Appt, and T. B. Clarkson, "Effects of bazedoxifene acetate with and without conjugated equine estrogens on the breast of postmenopausal monkeys," Menopause, vol. 19, no. 11, pp. 1242-1252, 2012.

[28] P. Oliva, C. Roncoroni, E. Radaelli et al., "Global profiling of TSEC proliferative potential by the use of a reporter mouse for proliferation," Reproductive Sciences, vol. 20, no. 2, pp. 119-128, 2013.

[29] Y. Kharode, P. V. N. Bodine, C. P. Miller, C. R. Lyttle, and B. S. Komm, "The pairing of a selective estrogen receptor modulator, bazedoxifene, with conjugated estrogens as a new paradigm for the treatment of menopausal symptoms and osteoporosis prevention," Endocrinology, vol. 149, no. 12, pp. 6084-6091, 2008.

[30] K. F. Ethun, C. E. Wood, J. M. Cline, T. C. Register, S. E. Appt, and T. B. Clarkson, "Endometrial profile of bazedoxifene acetate alone and in combination with conjugated equine estrogens in a primate model," Menopause, vol. 20, no. 7 , pp. 777-784, 2013.

[31] M. E. Nuttall, G. B. Stroup, P. W. Fisher, D. P. Nadeau, M. Gowen, and L. J. Suva, "Distinct mechanisms of action of selective estrogen receptor modulators in breast and osteoblastic cells," American Journal of Physiology - Cell Physiology, vol. 279, no. 5, pp. C1550-C1557, 2000.

[32] J. S. Crabtree, B. J. Peano, X. Zhang, B. S. Komm, R. C. Winneker, and H. A. Harris, "Activity of three selective estrogen receptor modulators on hormone-dependent responses in the mouse uterus and mammary gland," Molecular and Cellular Endocrinology, vol. 287, no. 1-2, pp. 40-46, 2008.

[33] M. Sato, M. K. Rippy, and H. U. Bryant, "Raloxifene, tamoxifen, nafoxidine, or estrogen effects on reproductive and nonreproductive tissues in ovariectomized rats," The FASEB Journal, vol. 10, no. 8, pp. 905-912, 1996.

[34] R. Armamento-Villareal, S. Sheikh, A. Nawaz et al., "A new selective estrogen receptor modulator, CHF 4227.01, preserves bone mass and microarchitecture in ovariectomized rats," Journal of Bone and Mineral Research, vol. 20, no. 12, pp. 2178-2188, 2005.

[35] R. A. Lobo, J. V. Pinkerton, M. L. S. Gass et al., "Evaluation of bazedoxifene/conjugated estrogens for the treatment of menopausal symptoms and effects on metabolic parameters and overall safety profile," Fertility and Sterility, vol. 92, no. 3, pp. 1025-1038, 2009.
[36] J. V. Pinkerton, W. H. Utian, G. D. Constantine, S. Olivier, and J. H. Pickar, "Relief of vasomotor symptoms with the tissueselective estrogen complex containing bazedoxifene/conjugated estrogens: a randomized, controlled trial," Menopause, vol. 16, no. 6, pp. 1116-1124, 2009.

[37] R. Kagan, R. S. Williams, K. Pan, S. Mirkin, and J. H. Pickar, "A randomized, placebo- and active-controlled trial of bazedoxifene/conjugated estrogens for treatment of moderate to severe vulvar/vaginal atrophy in postmenopausal women," Menopause, vol. 17, no. 2, pp. 281-289, 2010.

[38] S. Mirkin and B. S. Komm, "Tissue-selective estrogen complexes for postmenopausal women," Maturitas, vol. 76, no. 3, pp. 213-220, 2013.

[39] J. V. Pinkerton, J. A. Harvey, K. Pan et al., "Breast effects of bazedoxifene-conjugated estrogens: a randomized controlled trial," Obstetrics \& Gynecology, vol. 121, no. 5, pp. 959-968, 2013.

[40] M. Rossini, S. Lello, I. Sblendorio et al., "Profile of bazedoxifene/conjugated estrogens for the treatment of estrogen deficiency symptoms and osteoporosis in women at risk of fracture," Drug Design, Development and Therapy, vol. 7, pp. 601-610, 2013.

[41] R. Lindsay, J. C. Gallagher, R. Kagan, J. H. Pickar, and G. Constantine, "Efficacy of tissue-selective estrogen complex of bazedoxifene/conjugated estrogens for osteoporosis prevention in at-risk postmenopausal women," Fertility and Sterility, vol. 92, no. 3, pp. 1045-1052, 2009.

[42] J. V. Pinkerton, J. A. Harvey, R. Lindsay et al., "Effects of bazedoxifene/conjugated estrogens on the endometrium and bone: a randomized trial," The Journal of Clinical Endocrinology and Metabolism, vol. 99, no. 2, pp. E189-E198, 2014.

[43] W. Utian, H. Yu, J. Bobula, S. Mirkin, S. Olivier, and J. H. Pickar, "Bazedoxifene/conjugated estrogens and quality of life in postmenopausal women," Maturitas, vol. 63, no. 4, pp. 329$335,2009$.

[44] J. V. Pinkerton, K. Pan, L. Abraham et al., "Sleep parameters and health-related quality of life with bazedoxifene/conjugated estrogens: a randomized trial," Menopause, vol. 21, no. 3, pp. 252-259, 2014.

[45] J. H. Pickar, I. T. Yeh, G. Bachmann, and L. Speroff, "Endometrial effects of a tissue selective estrogen complex containing bazedoxifene/conjugated estrogens as a menopausal therapy," Fertility and Sterility, vol. 92, no. 3, pp. 1018-1024, 2009.

[46] D. F. Archer, V. Lewis, B. R. Carr, S. Olivier, and J. H. Pickar, "Bazedoxifene/conjugated estrogens (BZA/CE): incidence of uterine bleeding in postmenopausal women," Fertility and Sterility, vol. 92, no. 3, pp. 1039-1044, 2009.

[47] J. A. Harvey, J. V. Pinkerton, E. C. Baracat, H. Shi, A. A. Chines, and S. Mirkin, "Breast density changes in a randomized controlled trial evaluating bazedoxifene/conjugated estrogens," Menopause, vol. 20, no. 2, pp. 138-145, 2013.

[48] J. H. Pickar and B. S. Komm, "Selective estrogen receptor modulators and the combination therapy conjugated estrogens/bazedoxifene: a review of effects on the breast," Post Reproductive Health, vol. 21, no. 3, pp. 112-121, 2015.

[49] J. E. Rossouw, G. L. Anderson, R. L. Prentice et al., "Risks and benefits of estrogen plus progestin in healthy postmenopausal women," JAMA, vol. 288, no. 3, pp. 321-333, 2002.

[50] G. L. Anderson, M. Limacher, A. R. Assaf et al., "Effects of conjugated equine estrogen in postmenopausal women with hysterectomy," JAMA, vol. 291, no. 14, pp. 1701-1712, 2004. 
[51] S. Palacios, S. L. Silverman, T. J. de Villiers et al., "A 7-year randomized, placebo-controlled trial assessing the long-term efficacy and safety of bazedoxifene in postmenopausal women with osteoporosis: effects on bone density and fracture," Menopause, vol. 22, no. 8, pp. 806-813, 2015.

[52] J. C. Stevenson, A. Chines, K. Pan, K. A. Ryan, and S. Mirkin, "A pooled analysis of the effects of conjugated estrogens/bazedoxifene on lipid parameters in postmenopausal women from the Selective Estrogens, Menopause, and Response to Therapy (SMART) trials," The Journal of Clinical Endocrinology \& Metabolism, vol. 100, no. 6, pp. 2329-2338, 2015.

[53] D. Black, M. Messig, C. R. Yu et al., "The effect of conjugated estrogens/bazedoxifene therapy on body weight of postmenopausal women: pooled analysis of five randomized, placebocontrolled trials," Menopause, vol. 23, no. 4, pp. 376-382, 2016. 


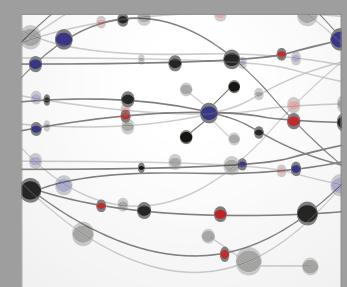

The Scientific World Journal
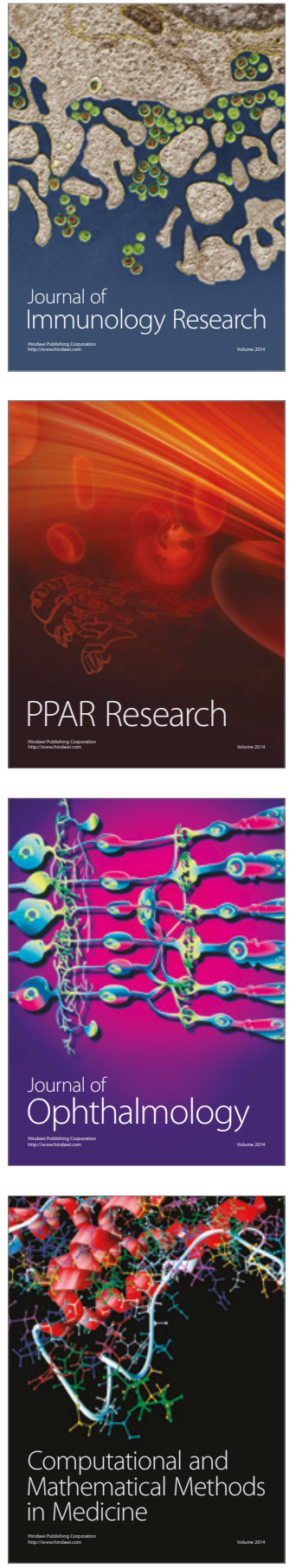

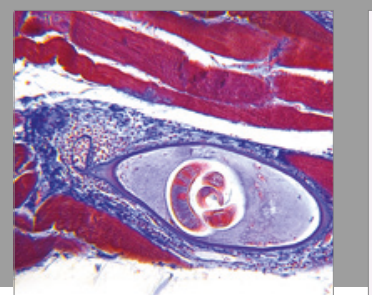

Gastroenterology Research and Practice
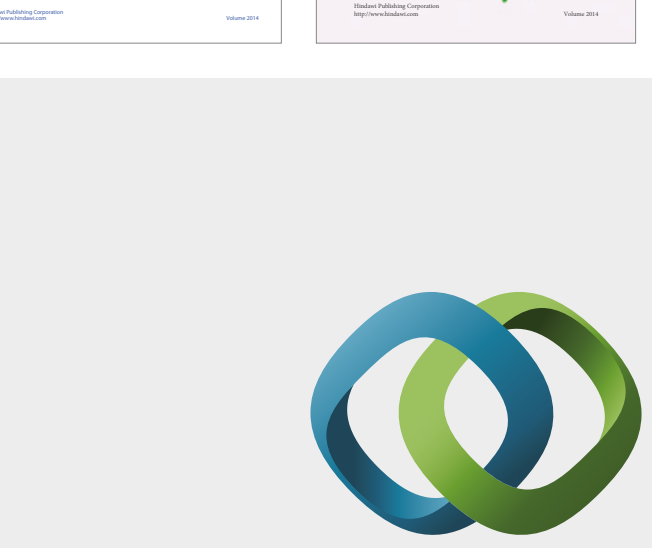

\section{Hindawi}

Submit your manuscripts at

https://www.hindawi.com
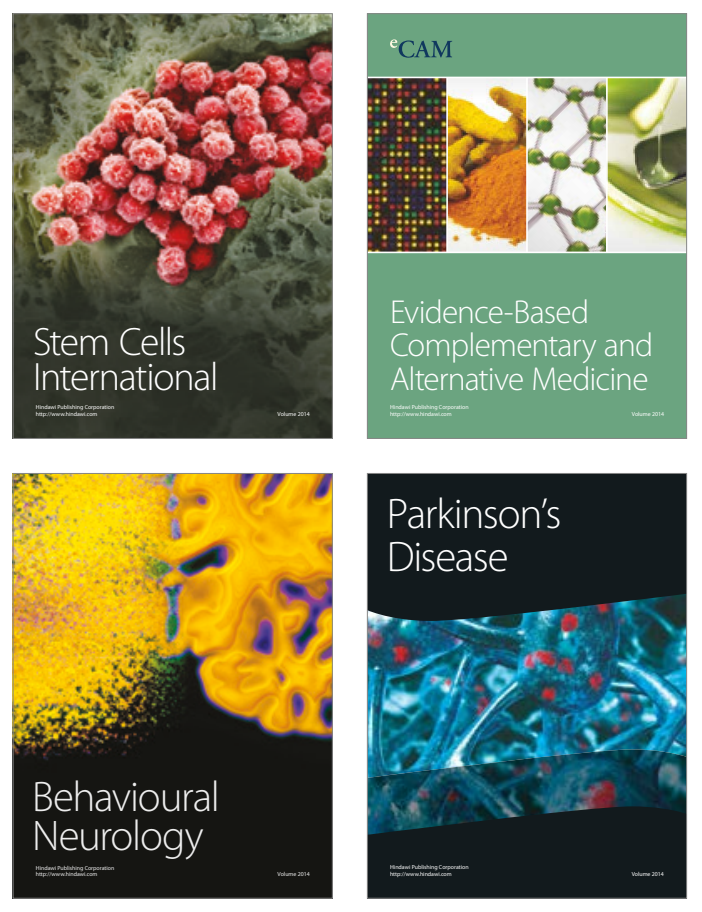
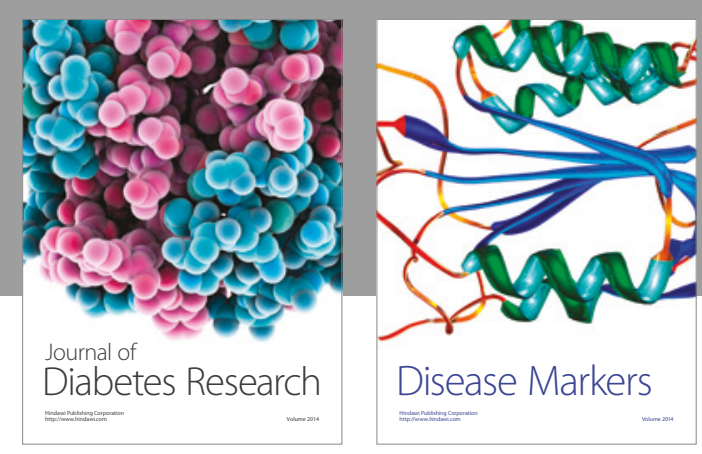

Disease Markers
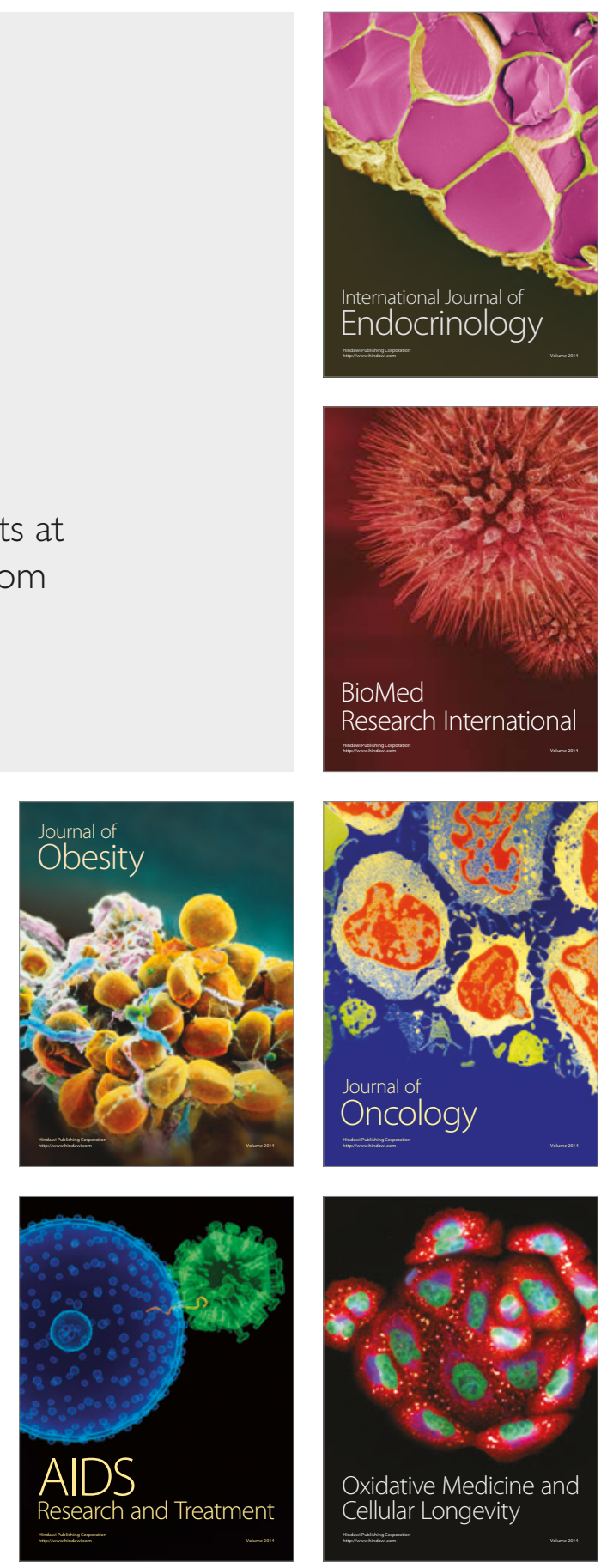